\title{
EL MITO INAGOTABLE. ESTUDIO DE LAS REESCRITURAS DEL MITO DE SIGFRIDO A LO LARGO DE TRECE SIGLOS
}

\author{
Victor Millet Schröder \\ Universidade de Santiago de Compostela
}

\section{RESUMEN}

Este trabajo analiza todas las principales manifestaciones del mito de Sigfrido, desde las más tempranas de época anglosajona, pasando por los grandes textos de la alta Edad Media, hasta su utilización moderna por el nacionalismo del s. XIX. El repaso permite no sólo comprobar la lógica de adaptación según la intención de cada uno de los textos, sino también realizar una historia de utilización de la leyenda en la que se descubre, por un lado, la constante ideológica en la apropiación del relato y, por el otro, cómo la leyenda de Sigfrido es el último superviviente de un tipo de relato heroico, el del héroe-rey, que empieza a ser reemplazado ya en la literatura de la alta Edad Media.

Palabras Clave: sigurd, Sigfrido, nibelungos, volsungos, héroes germánicos.

\section{THE INEXHAUSTIBLE MYTH. STUDY OF THE REWRITINGS OF THE SIEGFRIED MYTH OVER THIRTEEN CENTURIES}

\section{Abstract}

This paper analyses all major appearances of the myth of Siegfried, from the earliest AngloSaxon texts, through the great narratives of the high Middle Ages, to its modern use by 19th century nationalism. The review allows not only to verify the logic of adaptation according to the intention of each of the texts, but also to make a history of the use of the legend which reveals, on the one hand, the ideological constant in the appropriation of the story and, on the other hand, how the legend of Siegfried is the last survivor of a type of heroic tale, that of the hero-king, which begins to be replaced in the the literature of the high Middle Ages. KEYWORDs: sigurd, Siegfried, nibelungs, wolsungs, germanic heroes. 
Llamamos 'mitos' a aquellos relatos que, con el paso de los tiempos, han sido objeto de numerosas y diversas interpretaciones, apropiaciones y utilizaciones. No pretendo, con esta sencilla afirmación, establecer una nueva teoría del mito ni acabar con las discusiones histórico-literarias ${ }^{1}$, sino simplemente sentar un punto de partida para mi exposición. Cuantas más veces y en más grandes obras haya sido reelaborado un relato, más derecho adquiere de ser llamado 'mito'. Un mito sería entonces un relato que narra algo que apela a públicos de lugares y épocas distintos y que por lo tanto toca alguna fibra de antropología literaria, alguna constante del narrar universal. Esa es la causa de que reaparezca una y otra vez y de que se imponga a todo tipo de usos y apropiaciones. El mito es, en esta acepción, una cantera de relatos, una entidad narrativa básica que alimenta una y otra vez nuevas narraciones. Quiero mostrar aquí el funcionamiento de este tipo de relatos, exponiendo las potencialidades de uno de los mitos germanos más conocidos, más problemáticos y -quizás precisamente por ello- más longevos: el de Sigfrido. Los mitos medievales resultan especialmente interesantes para el estudio, dado que generalmente cuentan con testimonios que se distribuyen a lo largo de varios siglos y en diversas literaturas y porque muchos incluso cuentan con una recepción moderna. El de Sigfrido sin duda es el más destacado de ellos².

Pero empiezo con un matiz: en esta acepción a la que me aproximo, el mito resulta un ente abstracto, algo que no existe de forma pura o genuina, sino que sólo es una idea, una entidad narrativa que vive gracias a que diversos autores lo han utilizado para sus textos, adaptándolo a sus necesidades, a sus contextos y a sus ideologías. Lo que conocemos no son mitos, sino textos que nos relatan un mito. El 'mito' es aquello que abstraemos de las distintas versiones que tenemos a mano o en la memoria. Se constituye con las constantes que se repiten en todas ellas, pero también en los espacios de variabilidad y de interpretación concreta que ofrecen a cada versionador. En consecuencia, voy a comenzar con la parte abstracta, con el 'mito' de Sigfrido, antes de entrar a ver los 'relatos' de Sigfrido.

${ }^{1}$ H. Blumenberg, Arbeit am Mythos. Frankfurt am Main, Suhrkamp, 1979. M. Fuhrmann (ed.), Terror und Spiel. Probleme der Mythenrezeption. München, Fink, 1971. P. Tepe (ed.), Mythos \& Literatur. Aufbau einer literaturwissenschaftlichen Mythosforschung. Würzburg, Königshausen \& Neumann, 2001.

2 Véanse también las reflexiones en torno a héroe y mito en el estudio de K. von SEE, "Germanische Heldensage. Ein Forschungsbericht». Göttingische Gelehrte Anzeigen, vol. 218 (1966), pp. 52-98 (reimpreso en K. von SeE, Edda, Saga, Skaldendichtung. Aufsätze zur skandinavischen Literatur des Mittelalters. Heidelberg, Winter, 1981, pp. 107-153). En versión resumida también en K. voN SEE, Germanische Heldensage. Stoffe-Probleme-Methoden. Wiesbaden, Athenaion, 1981. 
A Sigfrido se le conoce en todos los ámbitos culturales germanos: es mencionado brevemente en el Beowulfanglosajón, desempeña un papel importante en las literaturas escandinavas occidentales y es famoso sobre todo en territorio alemán continental ${ }^{3}$. En alemán su nombre es Siegfried o Sîfrît, que comúnmente se interpreta como una combinación de Sieg (del germ. sigu) 'victoria' y de Fried (del germ. fridu) 'paz', lo que significaría 'victoria pacífica' o 'paz victoriosa'. Pero es posible también que el significado genuino del segundo componente del nombre proviniera de fridh, que significa 'bello, apacible', siendo entonces el nombre 'la bella victoria', o bien 'la belleza de la victoria'. En Escandinavia se le conoce como Sigurd. El componente final de este nombre correspondería al germ. vardu, 'guarda, protector', significando la combinación 'el protector o garante de la victoria's . Pero el nombre, en todo caso, nos dice poco del personaje.

Sigfrido es el héroe que mata al dragón. En la narrativa tradicional, el dragón es el máximo representante de la bestia, el terror, lo invencible, lo no humano, el caos, el mal (sobre todo en la tradición cristiana)5. Quien mata a la bestia es por lo tanto un héroe que ha sido capaz de sobreponerse a las limitaciones humanas para superarla en una terrible lucha. Este proceso, sin embargo, implica una cierta deshumanización: el héroe tiene que convertirse parcialmente en bestia para poder vencer a su oponente. Como en Sin perdón de Clint Eastwood, o como en Ghost Rider, de Nicolas Cage, el héroe tiene que mutar hacia lo bestial; y cito estos dos ejemplos para evidenciar que se trata de una constante narrativa, no de una influencia medieval. Después de vencer a la bestia, sin embargo, el héroe necesita pasar por un proceso de rehumanización si quiere reincorporarse a la sociedad. Generalmente este proceso se representa como enfriamiento, dado que la batalla y la bestialidad están vinculadas al fuego y al calor. Así, Tristán se sumerge en una laguna tras vencer al dragón y el héroe irlandés CuChulainn tiene que ser enfriado en tres tinas de agua helada sucesivamente ${ }^{6}$. El Ghost Rider tiene que esperar a que se apague el fuego

3 Todavía resultan informativos tanto el clásico libro de H. Schneider, Germanische Heldensage. I: Deutsche Heldensage. Berlín, de Gruyter 1962, como el el ricamente ilustrado de E. Ploss, Siegfried-Sigurd, der Drachenkämpfer. Untersuchungen zurgermanisch-deutschen Heldensage. Colonia / Graz, Böhlau, 1966. Pero ambos están metodológicamente anticuados. Puede verse la información más actualizada sobre esta figura en V. Millet, Germanische Heldendichtung im Mittelalter. Eine Einführung. Berlín / Nueva York, de Gruyter, 2008. O en la versión española del mismo que apareció bajo el título Héroes de libro. Poesía heroica en las culturas anglogermánicas medievales. Santiago de Compostela, Universidad, 2007.

${ }^{4}$ E.W. Förstemann, Altdeutsches Namenbuch, vol. 1: Personennamen. Ed. rev. Hildesheim, Olms 1966.

5 L. RöHrich, «Drache, Drachenkampf, Drachentöter», en K. Ranke et al. (eds.), Enzyklopädie des Märchens, Berlín, de Gruyter, 1981, vol. III, cols. 787-820.

${ }^{6}$ Gottfried von Straßburg: Tristan und Isolde, ed. de W. Haug y M. G. Scholz. Frankfurt am Main, Insel, 2011. Versión española en V. MiLlet (ed.), Eilhart von Obert-Gottfried von Strassburg: 
que lo envuelve para volver a ser humano; y cuando se pasan los efectos del 'aguardiente', también el personaje de Sin perdón vuelve a ser el granjero viejo de antes.

No lograr ese proceso de rehumanización significa no deshacerse de las cualidades de la bestia adquiridas en el combate y por tanto será una condena eterna para el héroe, que nunca volverá a poder reintegrarse plenamente en la sociedad. Esto es lo que le sucede a Sigfrido y lo que lo distingue de cualquier otro héroe. Al no completar la rehumanización permanece en él la marca de la bestia en forma de una cualidad sobrehumana o bestial. Sigfrido es el héroe que arrastra el estigma de la mítica batalla contra la bestia en forma de una piel que ningún arma puede herir. Lo veremos en seguida con más detalle.

Otro elemento caracteriza los relatos sobre este héroe: la victoria sobre el dragón le permite llevarse el tesoro que este custodiaba. La bestia y el oro son dos motivos que se asocian por la lógica de su simbolismo: aquel que supera a la bestia, al enemigo invencible, es un guerrero poderosísimo, un héroe (hoy diríamos un superhéroe). Ahora bien, en las sociedades arcaicas y heroicas, es decir, previas a la existencia de los estados, la lealtad hacia el líder se mantiene mediante la dádiva: el rey es generoso, hace regalos y esos regalos mantienen a los guerreros cerca de él 7 . En este contexto, el inmenso e inagotable tesoro es símbolo de ese poder, es el instrumento para materializarlo. Por eso en las poesías heroicas occidentales el oro no es un material con valor para el intercambio, sino un símbolo de poder, indivisible, infraccionable. Se pueden extraer piezas de él para regalarlas a guerreros afines, pero eso no merma el tesoro en tanto que símbolo de poder, porque la dádiva hecha al guerrero implica su lealtad y confirma y afianza el poder de quien la realiza ${ }^{8}$.

Hasta aquí el 'mito' de Sigfrido, es decir, el resumen de lo que es común a todos los relatos sobre él. Es un relato que pertenece a un ámbito marcadamente fantástico. La historia de Sigfrido debió de ofrecer a la vez fascinación e irritación; sobre todo por su vertiente más ligada a fantasiosos relatos de monstruos prehistóricos y trazos sobrehumanos. Precisamente por los rasgos ahistóricos de sus hazañas, Sigfrido es el más mítico de los héroes germánicos medievales, un héroe sacado de otro tiempo, de un tiempo mítico en el sentido de previo a la historia. Los demás héroes medievales son todos 'reales' e 'históricos' en el sentido de que son individuos de la aristocracia guerrera de la época de las migraciones y en los que la nobleza altomedieval que constituye su público se ve reflejada. Sigfrido nunca encajará del todo en este panorama y por ello es un héroe muy solitario. Arrastra consigo el estigma de su proeza mítica, la piel endurecida de su lucha contra el dragón; o la piel de cuerno, como la definen los textos alemanes tardíos, que llaman al personaje Hürnen Seyfried, es decir, Sigfrido córneo, o Sigfrido el de la piel de cuerno.

Tristán e Isolda. Madrid, Siruela, 2002. R. Thurneysen, Die irische Helden- und Königsage bis zum siebzehnten Jahrhundert. Halle, Niemeyer, 1921

7 Véanse ahora los estudios en H. Sahm, W. Heizmann y V. Millet (eds.), Gold in der europäischen Heldensage. Berlín, de Gruyter, 2019.

8 A. Cowell, The Medieval Warrior Aristocracy. Gifts, Violence, Performance and the Sacred. Woodbridge, Boydell \& Brewer, 2007. 
Los textos más antiguos que nos relatan la historia de Sigfrido son cuatro: uno anglosajón, uno alemán y dos escandinavos. El texto anglosajón es, cómo no, el Beowulf, un poema de datación incierta (siglos viII o IX) compuesto en verso aliterativo por un autor anónimo. El texto alemán es el Cantar de los Nibelungos, un poema épico compuesto en torno a 1200 en el sureste de la actual Alemania en el entorno del obispo de Passau. La versión escandinava la encontramos, por un lado, en la famosa colección de poemas narrativos conocida bajo el nombre de Edda poética. Esta colección de cantares es de la segunda mitad del siglo xiII y contiene textos de origen y estilo bastante diverso; algunos podrían ser bastante antiguos, pero la mayoría parecen del siglo XIII. Narran escenas o episodios particulares, pero están ordenados de tal manera que, en su conjunto, forman un amplio relato sobre el linaje y la vida de Sigurd. Y ese relato de conjunto que ofrecen los poemas de la Edda se corresponde, con bastante precisión, con el que nos ofrece el otro texto escandinavo, la Saga de los Volsungos, que es al menos medio siglo posterior ${ }^{9}$. Por ello, aunque haya que distinguirlos porque son dos obras independientes, a menudo los trataré como un único relato.

El Beowulf es sin duda el testimonio más antiguo de los aquí aducidos ${ }^{10}$. Allí se hace referencia (vv. 874-902) a las hazañas de Sigmund, el hijo de Wels; la crítica concuerda en que se trata sin duda de Sigfrido, pues tanto la filiación al linaje de Wels (los Volsungos) como el hecho de que Sigmundo aparezca como padre de Sigfrido en todas las tradiciones posteriores apuntan hacia una identidad de relatos. De la hazaña el texto dice que el héroe atravesó al temible dragón, guardián del tesoro, con tanta furia que la espada quedó clavada en la pared rocosa; el dragón se fundió en su fuego y el héroe se llevó el tesoro en un barco. Aquí aparece el tesoro, pero ninguna referencia al proceso de rehumanización.

El Cantar de los Nibelungos nos dice poco sobre Sigfrido y el dragón ${ }^{11}$. Pero la estrofa 100 nos da un detalle importante: tras matar al dragón el héroe se baña

9 Tanta es la proximidad que la famosa 'laguna' del Codex Regius, el manuscrito que contiene esa colección (Rejkjavík, Landsbókasafn, GKS 2365 4), al que le falta un cuaternión después del folio 32, suele completarse con la información narrada por la Saga en ese punto. No hay, lógicamente, evidencia científica de que ambos códices coincidieran en su relato en ese punto, y no faltan aspectos conflictivos, pero sirve para hacernos una idea de la acción. Vid. Th. M. Andersson, «The lays in the lacuna of Codex Redius», en U. Dronke et al. (eds.), Speculum Norroenum. Norse Studies in Memory of Gabriel Turville-Petre, Odense, Odense University Press, 1981, pp. 6-26.

${ }_{10}$ Beowulf. An edition with relevant shorter texts, ed. de B. Mitchell y F.C. Robinson. Oxford, Blackwell, 1998. La traducción más utilizada sigue siendo la de L. Lerate y J. Lerate, Beowulfy otros poemas anglosajones. Madrid, Alianza Editorial, 1986. Véase sobre esta obra también R.E. BJork y J.D. Niles (eds.), A Beowulf Handbook. Lincoln, University of Nebraska Press, 1997; R.J. Staver (ed.), A companion to Beowulf. Westport, Greenwood, 2005; A. Orchard (ed.), A critical companion to Beowulf. Cambridge, Brewer, 2003.

${ }^{11}$ Das Nibelungenlied. Nach der Handschrift 857 der Stiftsbibliothek St. Gallen, ed. de J. Heinzle. Frankfurt am Main, Deutscher Klassiker Verlag, 2013. La traducción española más 
en su sangre y su piel se vuelve tan dura que ningún arma puede herirla. La sangre del dragón, la bestia que escupe fuego, la imaginamos caliente, ardiente. En consecuencia, Sigfrido realiza lo contrario al proceso de enfriamiento que necesita todo héroe. Bañarse en la sangre de la bestia confirma la deshumanización del héroe, que queda sellada por el hecho de que su piel se vuelve dura, invulnerable. Esta propiedad no humana hará que Sigfrido jamás pueda volver a ser un ser humano como los demás, siempre será invencible. Y la invencibilidad, igual que la inmortalidad, es en literatura siempre un problema, un reto que se resuelve encontrando el punto débil y eliminando al invencible. Igual que en el caso de Aquiles (y resulta muy difícil pensar que el público cortesano medieval no fuera consciente de la analogía entre Sigfrido y Aquiles), también Sigfrido tiene un único punto donde se le puede herir: según la estrofa 902, una hoja de tilo cayó sobre su espalda entre los omóplatos y evitó que la sangre del dragón tocara la piel en ese punto. Por allí penetrará la lanza que lo matará.

El relato escandinavo sobre Sigfrido y su lucha contra el dragón es más detallado, más sofisticado y posiblemente más 'moderno' ${ }^{12}$. Aquí Sigurd aparece como aprendiz del traicionero herrero Regin, y como resultado de su aprendizaje forja una espada de características excepcionales. Un día Regin lo conduce hasta cerca de la guarida del dragón. Allí el héroe cava varias zanjas en el camino hacia el agua, se esconde en una de ellas y cuando el dragón pasa por encima le clava la espada de abajo arriba, hundiéndola hasta la empuñadura.

Este motivo de la estocada desde la zanja, por cierto, es en Escandinavia característico de Sigurd y permite identificarlo en una respetable serie de representaciones plásticas de época precristiana (la cristianización de Islandia se da en el 995 y la de Noruega en torno a 1020-1050) ${ }^{13}$. El más conocido es el petroglifo de Ramsund (figura 1), donde la inscripción rúnica - que nada tiene que ver con nuestro relato- forma en sus extremos una serpiente o dragón. Y ese dragón lo atraviesa con su espada un guerrero, aparentemente agachado, clavando la estocada de abajo arriba. Los demás elementos representados confirman la identificación con Sigurd: a la izquierda, una figura decapitada rodeada de martillo, fuelle, yunque y tenazas remite al herrero Regin. La figura que sostiene algo sobre lo que parece un fuego y que se lleva el pulgar de la otra mano a la boca es nuevamente Sigurd. El caballo

usada es la de E. Lorenzo Criado, Cantar de los Nibelungos. Madrid, Cátedra, 2004. Véase también W. McConnell (ed.), A companion to the Nibelungenlied. Columbia, Camden House, 1998; J.-D. Müller, Das Nibelungenlied. Berlín, Schmidt, 2015.

${ }^{12}$ La edición crítica más actual es The poetic Edda. 1: Heroic poems, ed. de U. Dronke. Oxford, Clarendon Press, 1969. En castellano sigue usándose L. Lerate (ed.), Edda Mayor. Poesía nórdica, siglos IX-XIII. Madrid, Alianza, 1986. Véase también el extenso comentario filológico de K. voN SEe et al. (eds.), Kommentar zu den Liedern der Edda. Heidelberg, Winter, 1997-2009.

13 P. Pulsiano y K. Wolf (eds.), Medieval Scandinavia: An Encyclopedia. Nueva York, Garland, 1993; R. Simek y H. PÁLsson (eds.), Lexikon der altnordischen Literatur. Stuttgart, Klett, 1987; C.J. Clover y J. Lindow (eds.), Old Norse-Icelandic Literature. A Critical Guide. Ithaca, Cornell, 1985. R. McTurk (ed.), A companion to Old Norse-Icelandic literature and culture. Malden, Blackwell, 2005. K. von SeE, Europa und der Norden im Mittelalter. Heidelberg, Winter, 1999. 


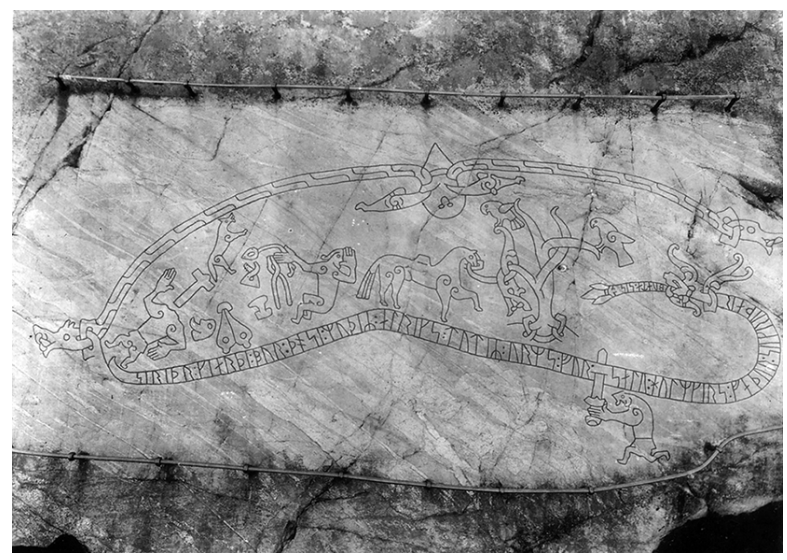

Figura 1. Petroglifo de Ramsund (Jäder, Södermanland, Suecia). Antikvarisk-topografiska arkivet, Riksantikvarieämbetet, Estocolmo. Foto: Harald Faith-Ell.

parece ir cargado con una caja (¿el oro?) y en el árbol de la derecha están los pájaros hacia los que Sigurd tiene girada la cabeza ${ }^{14}$.

Volviendo a los textos escandinavos: antes de matar a la bestia, el héroe se preocupa por la sangre que puede llenar su zanja, de modo que cava otras por las que la sangre pueda correr. Casi parece una inversión del motivo del baño en la sangre: el héroe evita hacer precisamente eso. Pero la sangre del dragón tendrá todavía un efecto importante. Tras matar al dragón aparece de nuevo Regin y le pide a Sigurd que le extraiga el corazón y lo ase en el fuego. Sigurd realiza esta tarea, pero cuando la sangre brota del corazón sobre el asador, Sigurd lo toca con el dedo para probar si está hecho, se quema e introduce el dedo en la boca. Al contacto de la sangre del dragón con la lengua, Sigurd entiende el lenguaje de los pájaros. Este será aquí el estigma de la lucha contra la bestia. Y los pájaros comentan entre sí que Regin es un traidor, que piensa matarlo para quedarse con el oro que custodiaba el dragón y que el héroe haría bien en guardarse de él. Ante esto, Sigurd mata a Regin y se lleva él solo el oro.

Los textos escandinavos cuentan, antes de narrar la vida de Sigurd, el origen del tesoro y cierta maldición divina que pesa sobre él. De ahí que el tesoro desempeñe un papel más significativo que en el Cantar de los Nibelungos, pues si bien no

${ }^{14}$ K. DüweL, «Zur Ikonographie und Ikonologie der Sigurddarstellungen», en H. Roth (ed.), Zum Problem der Deutung frühmittelalterlicher Bildinhalte, Sigmaringen, Thorbecke, 1986, pp. 221-272. M. Blindheim y A. Holtsmark, «Sigurds-Saga in der mittelalterlichen Bildkunst», en E. Vanbank (ed.), Nibelungenlied. Ausstellung zur Erinnerung an die Auffindung der Handschrift A des Nibelungenliedes im Jahre 1779 im Palast zu Hohenems, Bregenz, Vorarlberger Landesmuseum, 1979 , pp. 245-272. 


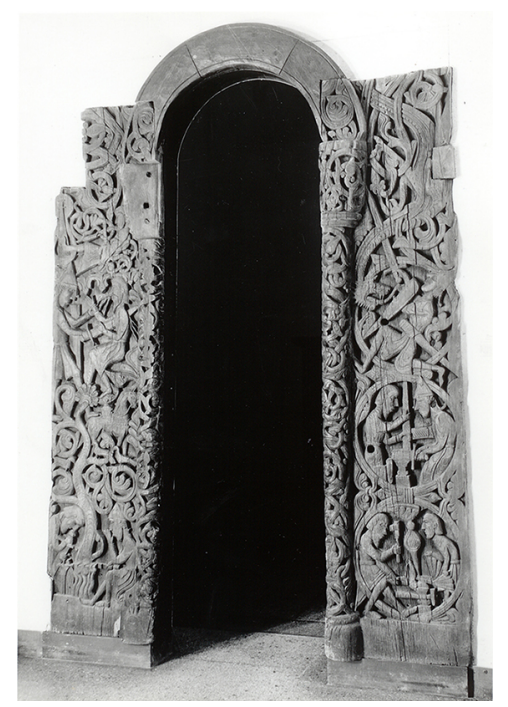

Figura 2. Portal de la iglesia de Hylestad (Valle, Aust-Agder, Noruega). Oslo, Museum of Cultural Heritage-Univeristy of Oslo. Foto: P.B. Maurtvedt.

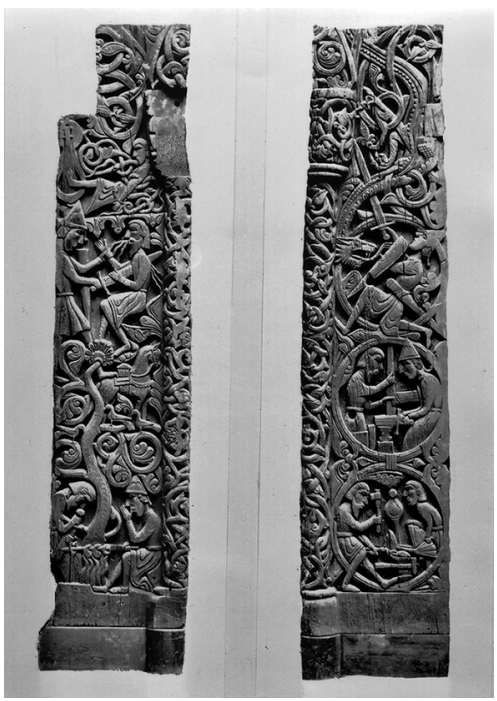

Figura 3. Detalle del portal de la iglesia de Hylestad (Valle, Aust-Agder, Noruega).

Oslo, Museum of Cultural HeritageUniveristy of Oslo. Foto: P.B. Maurtvedt.

cumple ninguna función narrativa directa, todos los desastres hasta la muerte de los últimos poseedores del tesoro a manos de Atila se justifican por esa maldición.

El relato sobre Sigfrido se mantiene de manera bastante estable en todos los testimonios escandinavos. Sorprende, sin embargo, encontrarlo incluso en lugares en donde no lo esperaríamos, concretamente en los laterales de las puertas de algunas iglesias de madera de Noruega, las conocidas como stavkirke. En la iglesia de Hylestad, de la que sólo se conserva el portal en el museo de Oslo ${ }^{15}$, podemos ver la secuencia entera de abajo arriba y de derecha a izquierda (figuras 2 y 3): Sigurd como ayudante del herrero Regin, la forja de la espada Gran, la muerte del dragón desde la zanja y de abajo arriba, el asado del corazón, Sigurd con el dedo quemado en la boca y Regin con la espada a medio desenvainar indicando la traición, y la muerte de Regin a manos de Sigurd, cuyo pie ya reposa sobre el caballo cargado con el tesoro. Tenemos que preguntarnos por qué este relato se representa a la entrada de una iglesia cristiana. Sin duda alguna, Sigurd ofrecía una clara analogía con el arcángel Miguel. Pero Sigurd no es un arcángel, sino que procede de un linaje mítico, se ve envuelto

15 S. Margeson, «Saga-Geschichten auf Stabkirchenportalen», en C. Ahrens (ed.), Frühe Holzkirchen im nördlichen Europa. Ausstellung des Helms-Museums, Hamburgo, Helms-Museum, 1981/82, pp. 459-480. E. Bergendahl Hohler, Norwegian Stave Church Sculpture. 2 vols. Oslo, Scandinavian University Press, 1999. 
en una traición, tiene que matar al traidor y se lleva el oro. Y todo ello no le servirá de nada, pues morirá asesinado. ¿Acaso el relato era sólo una advertencia? ¿Una invitación, a la entrada del templo, a dejar atrás el mundo de los héroes mitológicos y sus desgracias? La pregunta nos interesa porque estamos ante un relato heroico sacado de su contexto cultural habitual y sobre el que, por lo tanto, se ha operado algún tipo de reinterpretación o reescritura. Aunque no sepamos con seguridad cuál ${ }^{16}$.

Hasta aquí hemos visto lo que llamo el mito de Sigfrido y cómo se plasma en los textos. Pero ocurre que los textos no se limitan a este relato sobre el héroe, sino que van más allá. Porque en los textos, en el Cantar, las Edda y la Saga, la narración sobre este héroe aparece siempre combinada con la historia de Krimhilda y los reyes Burgundios. Parece como si, en las cortes altomedievales, el relato del héroe mítico sólo fuera posible integrándolo precisamente en una corte medieval y librando allí todo el potencial perturbador de lo heroico cuando entra en contacto con lo civilizado. El de los Burgundios es un universo narrativo complejo, debido a las diferencias entre las versiones y debido también a la estructura bipartita de esta materia: la primera parte gira en torno a Sigfrido, sus proezas y su asesinato, la segunda en torno a la muerte de los reyes Burgundios en la corte del rey Atila. De modo algo esquemático se puede decir lo siguiente: ambos relatos se combinan en una historia de doble conquista de la esposa. Sigurd casa con Krimhilda, la hermana del rey Gunther de Burgundia; y este a su vez casa con Brunhilda, es decir, que se crea una doble pareja de reyes. Pero ocurre que Brunhilda está vinculada a lo mítico y heroico igual que Sigfrido, de modo que el doble enlace se realiza parcialmente en contra de la lógica narrativa, y las tensiones que generan tanto esa vinculación como la superioridad heroica de Sigfrido llevan primero al asesinato de Sigfrido y luego al asesinato de Gunther a manos de Atila, pero como venganza instigada por Krimhilda, la viuda ${ }^{17}$.

En los textos escandinavos a Brunhilda se la asocia a las valquirias; Sigurd la conoce después de matar al dragón (es decir, cuando entiende el lenguaje de los

${ }^{16}$ Una dirección podría mostrarse en O. Gschwantler, «Christus, Thor und die Midgardschlange», en Festschrift für Otto Höfler zum 65. Geburtstag, Viena, Notring, 1968, vol. I, pp. 145-168.

17 Sobre la pre-historia del reltato ofrecido por el Cantar de los Nibelungos, véase W. Haug, «Szenarien des heroischen Untergangs», en A. Ebenbauer y J. Keller (eds.), 8. Pöchlarner Heldenliedgespräch. Das Nibelungenlied und die Europäische Heldendichtung, Viena, Fassbaender, 2006, pp. 103-120; años antes el mismo autor ya publicó otro trabajo sobre la materia nibelunga: W. HAUG, "Andreas Heuslers Heldensagenmodell: Prämissen, Kritik und Gegenentwurf». Zeitschrift für deutsches Altertum und deutsche Literatur, vol. 104 (1975), pp. 273-292 (reimpreso en W. HaUg, Strukturen als Schlüssel zur Welt. Kleine Schriften zur Erzählliteratur des Mittelalters. Tübingen, Niemeyer, 1989, pp. 277-292). Analiza las combinaciones de esquemas P. Strohschneider, «Einfache Regelnkomplexe Strukturen. Ein strukturanalytisches Experiment zum Nibelungenlied", en W. Harms y J.-D. Müller (eds.), Mediävistische Komparatistik. Festschrift für Franz Josef Worstbrock zum 60. Geburtstag, Stuttgart, Hirzel, 1997, pp. 43-75. 
pájaros), entabla una relación con ella y se prometen en matrimonio. Pero entonces interviene Gunther, rey de Burgundia, quien tiene interés en obtener a Brunhilda como esposa. Le proporcionan a Sigurd una poción de olvido y este ayuda entonces al rey Burgundio a obtener a Brunhilda y él obtiene a Krimilda como esposa. El efecto de la poción no cesa hasta después de las bodas. Es decir, que el vínculo entre Brunhilda y Sigfrido es fuerte y los casamientos se basan en sendos engaños: engaño a Sigurd y a Brunhilda. El engaño a Sigurd afecta precisamente a lo que es el estigma heroico en estos textos: el olvido contra la sabiduría.

Los textos escandinavos vinculan el tesoro y el propio linaje de Sigurd (los Volsungos o descendientes de Vols/Wels) con el dios Odín, es decir, con la mitología precristiana. La historia de Sigurd y de los Burgundios se desarrolla entonces como una sucesión de tragedias vinculadas a la maldición que pesa sobre ese oro. La maldición terminará cuando muera el último pariente relacionado él y el último que conoce su paradero. Cuando desaparece el oro parece por lo tanto cerrarse la etapa mítica, la pre-historia, un relato de terribles violencias y de emociones que desembocan siempre en derramamiento de sangre. Y a partir de ahí podrá arrancar la historia, postheroica y cristiana.

Así al menos parece haberlo entendido el autor de la Saga de Ragnar Loðbrókar o Saga de Ragnar el de las calzas de loden ${ }^{18}$. El único manuscrito conservado de la Saga de los Volsungos contiene únicamente esa saga y la de Ragnar. Dos sagas no muy extensas a las que se dedica un códice exclusivo. Ambos textos suelen fecharse en la segunda mitad del siglo XIII, hacia el final del reinado de Hákon Hákonarson (fallecido en 1263) o poco más tarde. La saga de Ragnar hace lo que en principio la leyenda de Sigfrido no hizo nunca en ninguna otra parte: inventar una línea sucesoria de Sigurd. Según este texto, antes de que el rey Burgundio le diera la pócima del olvido, Sigurd había tenido una relación con Brunhilda y de esa relación nació una hija, llamada Aslaug. La nińa, tras alguna vicisitud, es criada en un bosque, donde la encuentra tiempo más tarde Ragnar, rey de los Gautas. Ragnar se casa con ella. Entre otros hijos que la mujer da a luz, un día le anuncia uno que tiene «serpientes en los ojos» y al que llaman Sigurd. Los hijos de Ragnar, convertidos en poderosos guerreros, frenan la expansión de Suecia y conquistan Inglaterra. Sigurd tendrá una hija, Ragnhild, que será la madre de Harald Hárfargis (el de la cabellera hermosa), el primer rey de toda Noruega.

De este modo, las dos sagas construyen un complejo relato sobre el origen mítico de los reyes de Noruega. En primer lugar, convierten a Sigurd en descendiente de un linaje que en última instancia tiene su origen en el dios Odín. Al igual que otros relatos genealógicos medievales cuyos fundadores son semimíticos (la más famosa es la historia de la linda Melusina y la familia de Lusignan), los miembros de esta fami-

18 Völsunga saga og Ragnars saga loðbrókar, ed. de Ö. Thorsson. Reykjavík, Mál og menning, 1985. Versiones españolas en J.E. Díaz Vera (ed.), Saga de los Volsungos. Madrid, Gredos, 1998; así como en S. Ibañez (ed.), Saga de Ragnar Calzas Peludas. Saxo Gramático: Regnero. Valencia, Tilde, 1998. 
lia están caracterizados por una fiereza o por rasgos inhumanos que son estigmas del origen mítico. Ahí está, casi al final del árbol genealógico, el segundo Sigurd con las «serpientes en los ojos», quien sin embargo carece de la singularidad y descomunalidad de su tocayo y abuelo. Obviamente, al entrar en la dimensión humana de la familia real noruega, la marca de la descendencia divina que distingue a los elegidos como portadores de la herencia mítica se disuelve. Y por ello también la división del relato global en dos sagas: la primera, la de los Volsungos, se mantiene en el cronotopo mítico-heroico. La segunda, la de Ragnar, inventa un proceso de humanización de lo mítico hasta la fundación del linaje real. Y es llamativo que este proceso se realice doblemente por vía materna o femenina: las dos hijas de los dos Sigurd, nieta y abuela. Al mismo tiempo, estos textos son los únicos que nos presentan un Sigfrido nórdico o escandinavo. No es que el origen de Sigfrido haya sido tema de ningún otro texto, pero hasta estas sagas se nos presenta comúnmente como un héroe continental. Esto significaría que estaríamos ante una apropiación de mitos y héroes germanos para la construcción de una tradición cultural propia. No hay que olvidar que durante el reinado de Hákon Hákonarson se traducen un importante número de textos literarios continentales, preferentemente franceses, al nórdico antiguo y que esa europeización cultural moderna del siglo XIII no encaja mal con la construcción de una especie de origo gentis específicamente nórdica ${ }^{19}$. Sin embargo, el manuscrito único que conserva estas sagas no parece indicar un gran éxito de esta construcción.

Un último ejemplo escandinavo permite ver mejor cómo se concibió el paso del universo mítico-heroico al universo cultural cristiano. Se trata del cuento de Nornagest, de principios del siglo $\mathrm{XIV}^{20}$. Nornagest es un viejo desconocido que llega a la corte del rey Oláf. Durante la conversación vespertina, preguntado por su historia, cuenta que fue escudero de Sigurd y que lo acompañó en muchas de sus hazañas hasta su muerte y que luego acompañó a los hijos de Ragnar. Preguntado por su edad, responde que tiene trescientos años. A su cuna, aclara, acudieron las nornas (que son como las parcas) a tejer los hilos de su destino, pero la más joven, molesta por el trato que le dispensaban las demás, dispuso que viviera sólo el tiempo que durara la vela que ardía junto a la cuna. $\mathrm{Al}$ oír esto, otra norna apagó la vela y se la entregó a la madre para su custodia. Nornagest aún la lleva consigo y la muestra. Entonces se hace bautizar por el rey Óláf y luego enciende la vela; cuando se agota, Nornagest muere.

La construcción es excelente: el extraño viajero que se revela como hombre de otro tiempo (viajero en el tiempo), alguien que todavía ha vivido la edad de los héroes, esa de la que todos hablan pero que ya nadie ha vivido, porque está extinguida. El mítico y clásico motivo del nacimiento y de las nornas tejiendo el destino del héroe al lado de su cuna no sólo justifica la edad, sino que también lo vincula al

19 El contexto de composición de la Saga de Ragnar fue estudiado por K. von SEE, «Die kulturideologische Stellung der Völsunga saga ok Ragnars saga», en H. UeCKer (ed.), Studien zum Altgermanischen. Festschrift für Heinrich Beck, Berlín, de Gruyter, 1994, pp. 584-600.

${ }^{20}$ Fornaldar sogur Norðurlanda, ed. de G. Jónsson. Reykjavík, Islendingasagnaútgáfan, 1959, vol. I, pp. 305-335. 
tiempo en que todavía había nornas. Su destino, sin embargo, se cumple con el bautismo; la luz de la vida ha sido reservada como si él tuviera que vivir hasta la llegada de esa fe. Esa luz que ahora por fin se puede encender se agota pronto, permite al fin la muerte del viajero de otro tiempo y cierra definitivamente la era precristiana.

En el Cantar de los Nibelungos (y en la tradición continental alemana que deriva de él), Brunhilda es una mujer guerrera que sólo admite casarse con quien la supere en tres pruebas de fuerza. Gunther es incapaz de superar a esa amazona, eso se sabe de antemano, por eso tiene que ser Sigfrido quien la venza bajo la apariencia de Gunther. Aquí no hay vínculo previo entre Sigfrido y Brunhilda, pero esa guerrera forzuda del lejano norte que sólo casará con el más fuerte responde al mismo modelo arcaico de heroísmo del que proviene Sigfrido. El más fuerte es Sigfrido, de modo que la lógica quiere que sólo él pueda superar las pruebas. Ese nexo lógico (pero de una lógica heroica) entre Sigfrido y Brunhilda genera un potencial de conflicto enorme en la familia del rey de Burgundia. Ambos personajes arrastran consigo un estigma mítico que los hace inalcanzables para los humanos: la fuerza bruta que supera la de todos los demás ${ }^{21}$. Y esa correspondencia entre ambos hace que no sólo exista el riesgo de un cortocircuito amoroso a lo Tristán e Isolda ${ }^{22}$, sino que sobre todo su superioridad resulte una amenaza para el reino. Eso conduce inevitablemente al asesinato de Sigfrido, que aleja el peligro del invencible y deja a Brunhilda sin apoyo. La eliminación del invencible se presenta como una estrategia de rescate ante su infinita superioridad y el riesgo que emana de ella.

El autor del Cantar de los Nibelungos esconde lo mítico en espacios sustraídos a la visibilidad: el Sigfrido de la fuerza descomunal realiza las pruebas de la conquista escondido bajo el manto que lo hace invisible, mientras Gunther simula o gesticula realizar las pruebas. Así, la fuerza mítica y arcaica actúa encubierta por las apariencias del máximo representante de la corte ${ }^{23}$. Sigfrido es en el Cantar un mozo hermoso, cortesano y refinado que, sin embargo, esconde una 'bestialidad' de orígen mítico que emerge unas pocas veces, amenazante y sobre todo arrolladora. Esa fuerza sale a relucir casi de modo natural en la guerra del principio, donde mata y apresa a los jefes adversarios en una furibunda correría; más adelante la utilizará conscientemente, pero escondido bajo ese manto que lo hace invisible, en las prue-

${ }^{21}$ Recordemos que en los textos escandinavos se sustituye por la sabiduría de Brunhilda y la comprensión del lenguaje de los pájaros de Sigurd.

${ }^{22}$ H. Kunn, "Tristan, Nibelungenlied, Artusstruktur», en Sitzungsberichte der Bayerischen Akademie der Wissenschaften, philos.-hist. Kl., 1973/5, Múnich, Akademie, 1973 (=Colloquio italo-germanico sul tema: I Nibelunghi, Roma, Accademia Nazionale dei Lincei, 1974, pp. 7-17). P. STroHSCHNEIDER (nota 16).

${ }^{23}$ Sobre este aspecto ampliamente J.-D. MüLLER, Spielregeln für den Untergang. Die Welt des Nibelungenliedes. Tübingen, Niemeyer, 1998. 
bas de fuerza para la conquista de Brunhilda. Y finalmente sale a relucir de manera casi cómica en la escena de caza previa a su asesinato, donde Sigfrido caza dos jabalíes, un león, un bisonte, un alce, cuatro uros, un ciervo y, por último, da alcance a pie a un oso y lo apresa con sus manos. Sigfrido parece inconsciente de su verdadero poder, de su insuperable fuerza y de su piel invulnerable por arma alguna; pero parece inconsciente sobre todo de lo amenazante que resulta lo mítico para los humanos corrientes. Así, cuando regresa de la cacería, suelta al oso al llegar al campamento y lo manda azuzar por los perros, de modo que en un instante todo el campamento del rey queda alborozado y patas arriba, hasta que el héroe vuelve a apresar el oso. Una broma pesada que revela todo el potencial de amenaza.

Al principio los Burgundios utilizan al gran héroe en su propio interés, primero para resolver una guerra, luego para obtener a la reina. Pero ya la conquista de Brunhilda, basada en el engaño y en la utilización de la fuerza de Sigfrido invisible tras los gestos del rey, muestra cómo el Cantar desarrolla una feroz crítica hacia la sociedad cortesana, a la que refleja como un poder de doble fondo, donde las apariencias refinadas cubren actos de fuerza bruta, donde lo visible no se corresponde con la realidad. A partir del asesinato de Sigfrido, son los propios reyes Burgundios quienes quebrantan la ley con nocturnidad y alevosía. Y caen en una espiral de traiciones y violencia que no sólo acabará en la matanza más descarnada de toda la historia de la literatura, sino que en ella cada vez resulta más patente que bajo el manto de refinamiento cortesano no se esconde otra cosa que guerreros arcaicos, la mítica tradición de los matadores de dragones ${ }^{24}$.

Pero otro aspecto pesa todavía más en el Cantar de los Nibelungos. El mundo heroico es siempre un mundo pre- o paracivilizatorio, pues en él impera la ley del más fuerte. El héroe, a diferencia de un protagonista, se impone siempre por ser el más fuerte. La prueba o las pruebas que debe superar el protagonista sirven, precisamente, para demostrar que es el más fuerte. En los relatos heroicos con conquista de esposa, el más fuerte obtiene a la más hermosa. Estas son constantes antropológicas de la narrativa que se pueden ver todavía en el cine de Hollywood. Pero donde impera la ley del más fuerte, no impera el Derecho. Y esta oposición entre Derecho y Fuerza es también una constante de la narrativa. Para el Cantar de los Nibelungos es, más aún que para el cine moderno, la contraposición entre civilización y barbarie. Brunhilda es una reina del ámbito heroico. Por eso impone las pruebas de fuerza a sus pretendientes y sólo se casará con quien la supere en las tres; a los demás los mata. Sólo el más fuerte puede conquistar a la más fuerte; y quien no es el más fuerte sucumbe. La utilización de los poderes míticos de Sigfrido (de su fuerza y su invulnerabilidad) por parte de los Burgundios se realiza precisamente quebrantando el Derecho y de paso también la ley heroica. Gunther conquista a Brunhilda enganándola por partida doble: engañándola en las pruebas de fuerza (que Gunther sólo simula realizar, mientras el verdadero actor es Sigfrido, invisible) y engañán-

${ }^{24}$ Véase también O. Ehrismann, Nibelungenlied. Epoche-Werk-Wirkung. München, Beck, 1987. H. Bekrer, The Nibelungenlied. A literary analysis. Toronto, University of Toronto Press, 1971. 
dola de nuevo en la boda formal en su corte, e incluso durante su reinado posterior. Pues donde ella, para quien únicamente rige la ley del más fuerte, sólo puede ver dominantes y dominados, la realidad cortesana presenta a personas con los mismos derechos, y eso genera conflicto en la reina.

La grandeza del Cantar de los Nibelungos reside, entre otras muchas cosas, en mostrar cómo el magnífico y ordenado mundo cortesano de los Burgundios, regido por el Derecho, se descompone lenta pero inexorablemente porque en él cada vez más se impone la ley del más fuerte, primero de manera ocasional, sutil y encubierta, luego cada vez más de modo abierto y declarado, hasta que sucumben en la muerte más heroica: la de hacerse matar para vencer. Como portador de los estigmas del mundo mítico-heroico, Sigfrido es una señal que apunta hacia la manera en que elementos de ese mundo están entrando en el universo cortesano, el del presente del autor y el público. Sigfrido puede desaparecer porque ese proceso de contaminación de los nobles cortesanos por la lógica heroica, el 'virus' de la sustitución del Derecho por la ley del más fuerte, ya se ha propagado, y se extenderá hasta la aniquilación total de la sociedad portadora.

La historia posterior del Cantar de los Nibelungos, la historia de su lectura y reelaboración en los siglos XIV y XV, revela también que ese rasgo mítico del personaje de Sigfrido era percibido como un punto problemático. Conservamos dos copias del Cantar, conocidas como los manuscritos $a$ y $n^{25}$, que reducen o netamente eliminan la parte de Sigfrido del poema y tratan, al mismo tiempo, de situar el resto de la acción en un marco histórico, como si fueran acontecimientos ocurridos a algún antepasado de la nobleza feudal. Para estos intentos de recontextualización histórica, la figura de Sigfrido probablemente resultaba molesta, porque incluso para el

25 Véanse para este apartado las consideraciones generales de L. Voetz, «Die NibelungenliedHandschriften des 15. und 16. Jahrhunderts im Überblick», en J. Heinzle y U. OвноF (eds.), Die Nibelungen. Sage-Epos-Mythos, Wiesbaden, Reichert, 2003, pp. 283-305; así como las de V. Mertens, "Nibelungische Metamorphosen. Zum Nibelungenlied im Spätmittelalter», en D. Buschinger y J.-F. Candoni (eds.), Les Nibelungen. Actes du Colloque du Centre d'Études Médiévales de l'Université de Picardie-Jules Verne, Amiens (12 et 13 Janvier 2001), Amiens, Université, 2001, pp. 99-110g. La versión a puede consultarse en Das Nibelungenlied. Paralleldruck der Handschriften A, B und C nebst Lesarten der übrigen Handschriften, ed. de M. BatTs, Tübingen, Niemeyer, 1971, pp. 795-796. La versión $n$ ha sido objeto de dos ediciones recientes: Eine spätmittelalterliche Fassung des Nibelungenliedes. Die Handschrift 4257 der Hessischen Landes- und Hochschulbibliothek Darmstadt, ed. de P. GöHLER, Viena, Fassbaender, 1999; y Das Nibelungenlied nach der Handschrift n, ed. de J. Vordestemann, Tübingen, Niemeyer, 2000. Sobre ella hay dos estudios imprescindibles: E.R. HaYmes, "Die Nibelungen im Spätmittelalter. Die Handschrift $n$ und ihre Umgebung», en Vom Mittelalter zur Neuzeit. Festschrift für Horst Brunner, Wiesbaden, Reichert, 2000, pp. 447-461; así como J. Heinzle, «Wiedererzählen in der Heldendichtung. Zur Fassung $n$ des 'Nibelungenliedes'", en J. Bumke y U. Peters (eds.), Retextualisierung in der mittelalterlichen Literatur, Berlín, Schmid, 2005, pp. 139-158. 
público del siglo xv estaba claro que este héroe, a diferencia de los demás, carecía de raíces históricas conocidas y que sus hazañas resultaban demasiado fantásticas. Es la inquietud ante la ficción por parte de quienes buscan una validez histórica, política o ideológica en la literatura.

Por el otro lado, otra parte del público parece haber gozado precisamente del lado mítico y fantasioso del Cantar que aportaba la figura de Sigfrido. Así, conservamos el índice de capítulos de una copia del poema que por lo demás está perdida (versión $m)^{26}$. Gracias a que los títulos resumen la acción de cada canto y que tenemos números de folios, podemos saber que esta versión en primer lugar dedicó siete u ocho folios a narrar la lucha de Sigfrido contra el dragón y cómo obtuvo el fabuloso tesoro. Es decir, que aquí se realizó un trabajo de edición y una ampliación del texto del Cantar. Pero a continuación esta versión introduce un capítulo de ocho folios sobre "cómo un dragón raptó a Krimhilda y la llevó a una alta montaña», luego otro capítulo de cuatro folios sobre «cómo Sigfrido liberó a la doncella con muchos y grandes trabajos» y finalmente uno de nueve folios sobre "cómo Sigfrido, tras vencer al dragón, regresó con la doncella a la corte». A la vista de todas estas amplificaciones del texto del Cantar, puede afirmarse que esta versión no pretendía situar los hechos en un marco histórico, como las anteriores, sino que operó de modo contrario, ampliando los episodios mítico-heroicos e introduciendo nuevas aventuras en el relato. Cabe señalar que, como al final el mito siempre se impone, los intentos de enmarcar la acción del Cantar en un contexto histórico fracasaron, pero la historia de Sigfrido, sus luchas contra dragones y su liberación de una princesa, fue leída hasta bien entrado el siglo XVII gracias a un cantar, Das Lied vom Hürnen Seyfrid, compuesto a finales del siglo XV o principios del Xvi y difundido a través de sucesivas ediciones impresas ${ }^{27}$.

Por último, conservamos el texto de una farsa de carnaval escrita en Vipiteno, en el Tirol, a principios del siglo $\mathrm{XVI}^{28}$. En ella se hace luchar a espada a seis pares de héroes de la literatura alemana. Vipiteno tenía una escuela de armeros que realizaba exhibiciones de esgrima y es muy probable que ese texto sirviera para vestir una de esas muestras. Porque en la presentación el anunciador pide apartar mesas y sillas para el combate, ruega a las damas que no se asusten por los fogonazos de las espadas y pide especial espacio para Sigfrido, a quien su piel de cuerno hace un poco patoso. Podemos imaginarnos al actor que hacía de Sigfrido recubierto de alguna protección que hiciera más graciosa y espectacular su actuación. Lo interesante de

${ }^{26}$ H. de Boor, «Die Bearbeitung m des Nibelungenliedes», en Beiträge zur Geschichte der deutschen Sprache und Literatur, vol. 81 (1959), pp. 176-195.

27 Das Lied vom Hürnen Seyfrid. Critical edition with introduction and notes, ed. de K.C. KInG. Manchester, University Press, 1958. Véase también K.C. KING, «Siegfried's Fight with the Dragon in the Edda and the Hürnen Seyfrid», en K.C. King, Selected Essays on Medieval German Literature, Londres, Institute of Germanic Studies, 1975, pp. 7-13; así como R. BREYER, «Der hürnen Seyfrid. Die Form des Inhalts», en K. Zatloukal (ed.), 3. Pöchlarner Heldenliedgespräch. Die Rezeption des Nibelungenliedes, Viena, Fassbaender, 1995, pp. 53-65.

${ }_{28}$ Das Recken spil, en Sterzinger Spiele. Die weltlichen Spiele des Sterzinger Spielarchivs nach den Originalhandschriften (1510-1535) von Vigil Raber und nach der Ausgabe Oswald Zingerles (1886), ed. de W.M. BAuER. Viena, Österreichischer Bundesverlag, 1982, pp. 9-27, 481-485 y 529. 
este detalle es que el elemento mítico, la piel endurecida por el baño en la sangre del dragón, se ha convertido en cómico, en materia de diversión carnavalesca.

Todo este material narrativo sobre Sigfrido, con las complicaciones semánticas que ya produjo en época medieval, desde las primeras apariciones de su relato, se convirtió a partir de principios del siglo XIX en el caldo para la transformación de Sigfrido en una figura de identificación nacional. El proceso a través del cual el Cantar de los Nibelungos se convirtió en un símbolo del nacionalismo alemán decimonónico constituye quizás uno de los fenómenos culturales más sorprendentes de la Alemania del siglo XIX.

Varios factores contribuyeron a ello ${ }^{29}$ : en primer lugar, la intensa recepción de la Germania de Tácito a partir del siglo xvi y el enaltecimiento de sus elogios a los pueblos germanos permitieron el sueño de una Germania prerromana entre lo idílico y lo heroico. En segundo lugar, la Reforma luterana genera una oposición hacia Roma; esta se incrementa a medida que el Imperio, que desde Carlomagno está en manos de la nobleza alemana, pierde fuerza, y se acrecienta con la guerra de los treinta ańos. Ello ofreció un terreno abonado para que (al principio de manera muy marginal) se creara un mito de lo germano según el cual la dominación romanocristiana era impuesta y significaba la degeneración de unos valores puros. A ello contribuyó también el descubrimiento de Grecia en la Alemania de mediados del siglo XVIII, que permitió acceder a un mundo clásico previo (y supuestamente más puro) a Roma ${ }^{30}$. Y el idilio de la Grecia antigua no tarda en tocarse con el idilio de la Germania antigua. Para entonces, el mundo cultural alemán buscaba ya una Ilíada alemana, un poema épico fundacional ${ }^{31}$, y el redescubrimiento del Cantar de los Nibelungos en esa misma época por un lado y las guerras napoleónicas por el otro hicieron que ese poema se convirtiera, a pesar de lo poco indicado que resultaba, en un texto de identificación nacional. Pero dado que esa identificación política no se podía basar en la acción del poema, pues las intrigas y asesinatos en la casa real de Borgoña unos cinco siglos antes de que existiera algo así como Alemania no calaban

${ }^{29}$ J. Heinzle y A. Waldschmidt (eds.), Die Nibelungen. Ein deutscher Wahn, ein deutscher Alptraum. Studien und Dokumente zur Rezeption des Nibelungenstoffs im 19. und 20. Jahrhundert. Frankfurt am Main, Suhrkamp, 1991. J. Heinzle, Die Nibelungen. Sage-Epos-Mythos. Wiesbaden, Reichert, 2004. K. vON SEE, Deutsche Germanen-Ideologie. Vom Humanismus bis zur Gegenwart. Frankfurt, Athenäum, 1970. H. BRACKERT, «Nibelungenlied und Nationalgedanke. Zur Geschichte einer deutschen Ideologie», en U. Hennig y H. Kolb (eds.), Mediaevalia litteraria. Festschrift für Helmut de Boor zum 80. Geburtstag, Múnich, Beck, 1970, pp. 343-367.

${ }^{30}$ Recuérdese, por ejemplo, la fundamental influencia que ejerció el librito de J.J. WincKeLmann, Gedanken über die Nachahmung der griechischen Werke in der Malerey und Bildhauerkunst. Dresden, Walther, 1756.

31 K. von See, «Das Nibelungenlied-ein Nationalepos?», en Heinzle / Waldschmidt (nota 28), pp. 43-110. 
como mito de origen, tuvo que basarse en los personajes. Aquí se inició un incesante proceso de aplicar, desde todas las perspectivas posibles, las virtudes de carácter que Tácito había reconocido a los germanos (aunque con el único objetivo de criticar la decadencia romana) a los personajes del Cantar: la nobleza, la pureza, la lealtad, etc. Eso caló a base de repetirlo incluso en la escuela, a pesar de que el Cantar sólo narra traiciones y contratraiciones.

$\mathrm{Al}$ mismo tiempo se redescubre también a Arminio, el guerrero querusco que en el ańo 9 d.C. derrotó al ejército romano del general Varro en el bosque de Teutoburgo. Esa victoria sobre Roma se convierte en el referente nacional no sólo durante las guerras napoleónicas, sino también mucho más tarde. Pero Arminio carece de texto, no hay un poema que lo narre y celebre, no hay mito. Por ello la figura de Sigfrido, que se debió de antojar la más semejante y que lleva la victoria en el nombre, se erige en complemento o sustituto de Arminio.

Paralelamente, además, se conocen y popularizan la Edda Poética y la Saga de los Volsungos. La imaginación romántica y la teoría de las cantilenas homéricas pronto convirtieron los poemas narrativos de la Edda en cantares primitivos, cosa que en su inmensa mayoría no son. En todo caso, como la tradición escandinava sitúa a Sigfrido en el centro de la acción, su mito se vio ahora reforzado. Y recibió su consolidación con la tetralogía operística de Richard Wagner El anillo del Nibelungo. Sigfrido es aquí, como en la Saga, el elegido de los dioses, descendiente de Odín y de vieja estirpe germana, representante de 'lo Alemán'. Sus valores son la fortaleza aristocrática y la disponibilidad para luchar ${ }^{32}$. La mitología política se aprovecha inmediatamente de esta revalorización de Sigfrido como imagen del poder (el fabuloso tesoro), la victoria sobre el enemigo exterior (el dragón) y la grandeza de la nueva patria unida. Así lo expresa ya el inicio del poema Die Siegestrunkenen («Embriagados de victoria») de Georg Herwegh de 1872, tras la guerra franco-prusiana:

Vorüber ist der harte Strauß,

Der welsche Drache liegt bezwungen,

Und Bismarck-Siegfried kehrt nach Haus

Mit seinem Schatz der Nibelungen ${ }^{33}$.
Ha terminado la dura contienda, el dragón francés yace vencido y Bismarck-Sigfrido regresa a casa con su tesoro de los nibelungos.

Como en las Edda y en la Saga de los Volsungos, el problema es que al final no sólo se impone el mito, sino también lo atávico y destructivo que conlleva. Así ocurrió 30 años más tarde: en marzo de 1909, en un discurso ante el Parlamento alemán, el príncipe Bernhard von Bülow, canciller imperial del Kaiser Guillermo II, definía la relación entre Alemania y el Imperio austrohúngaro como «lealtad de nibelungos» (Nibelungentreue), recordando el vínculo inquebrantable que une a los héroes en su combate mortal en la corte de Atila. Esa lealtad fue confirmada por el mariscal

32 P. Wapnewski, Der Ring des Nibelungen. Richard Wagners Weltendrama. Múnich, Piper, 1998. V. Mertens, «Das Nibelungenlied, Richard Wagner und kein Ende», en Heinzle / Klein / Овноғ (nota 28), pp. 459-496.

${ }_{33}$ G. Mahal (ed.), Lyrik der Gründerzeit. Tübingen, Niemeyer, 2015, p. 216. 


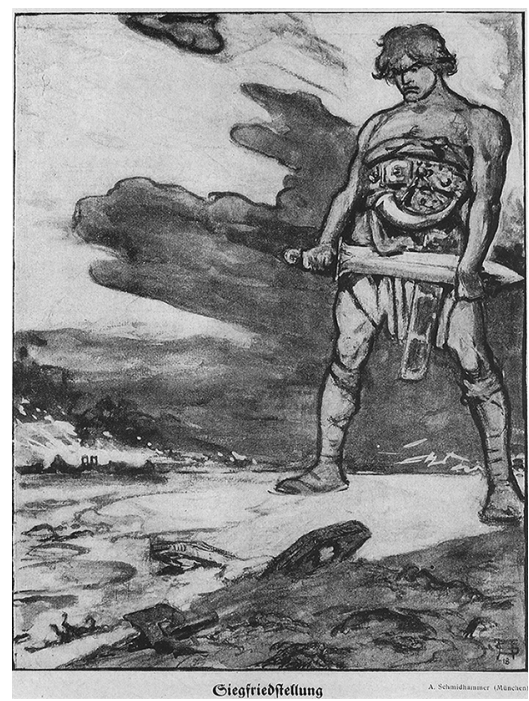

Figura 4. Siegfriedstellung. Ilustración de la revista Jugend del 9 de noviembre de 1918.

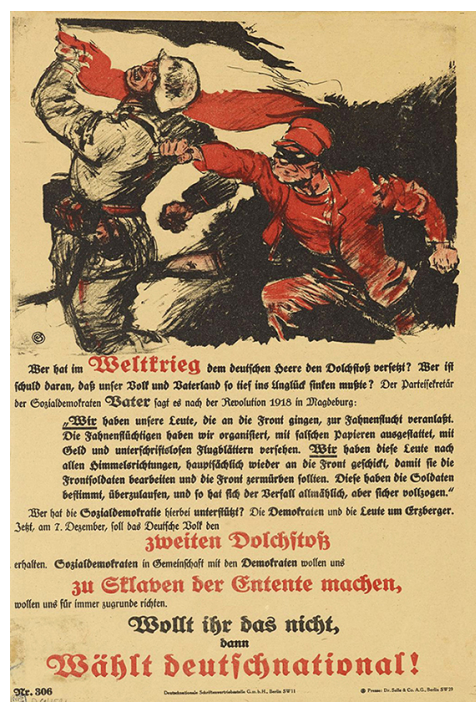

Figura 5. El relato de la puñalada en la espalda. Panfleto para las elecciones al Reichstag del 7 de diciembre de 1924.

Hindenburg en 1914, en las semanas decisivas antes del inicio de la primera guerra mundial, fue celebrada por numerosos patriotas encendidos y en su nombre los soldados alemanes fueron mandados por miles a morir en las trincheras, igual que las hordas de hunos son diezmadas en los combates en la corte de Atila del Cantar de los Nibelungos. Los planes estratégicos del ejército alemán estaban llenos de nombres en clave extraídos de la epopeya. Así, por ejemplo, la línea básica de defensa, el último cierre que tenía que impedir un avance enemigo, era denominada "posición de Sigfrido» (Siegfriedstellung). Esa era la defensa infranqueable, la combinación de posiciones tácticas en las que se podía confiar (figura 4$)^{34}$.

Después del desastre de 1918, en cambio, se fraguó entre actores y observadores del bando conservador y militarista el mito de la puńalada por la espalda, que explicaba la derrota del ejército alemán por el cese del apoyo de la población tras la revolución de noviembre de 1918. No faltó entonces tampoco quien comparara ese hecho con el Cantar de los Nibelungos (figura 5). El propio mariscal Hindenburg escribía en sus memorias de 1920: «Igual que Sigfrido cayó por la lanza traidora del siniestro Hagen cuando iba a beber de la fuente clara, así cayó también

${ }^{34}$ H. Münkler y W. Storch, Siegfrieden. Politik mit einem deutschen Mythos. Berlín, Rotbuch, 1988. 


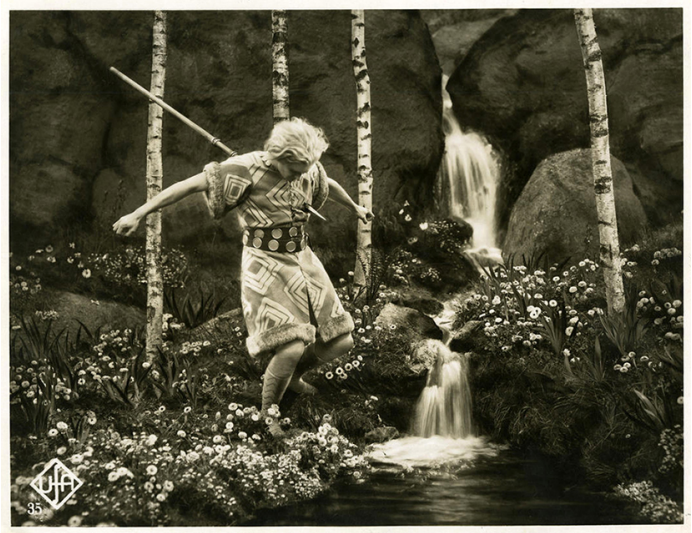

Figura 6. La muerte de Sigfrido. Fritz Lang, Die Nibelungen (1924-25), UfA.

nuestro agotado frente tras intentar en vano beber nueva vida del manantial agotado del apoyo de la patria ${ }^{35}$.

Sin duda alguna, el público de Fritz Lang pensó en ello cuando vio la escena del asesinato de Sigfrido (figura 6). Pero Lang es un narrador más neutral y, aunque toque muchas fibras, su monumental película de 1924-1925 no defiende ninguna corriente ideológica concreta, sino que precisamente trata de desmitificar ${ }^{36}$.

Tampoco le parecía quedar mucho recorrido entonces al mito de Sigfrido. Con la república de Weimar se consuma, finalmente, un cambio que en otras literaturas occidentales se había producido mucho antes: el del héroe-rey al héroevasallo. Así, el aristócrata Sigfrido es sustituido generalmente por otros héroes más llanos, héroes seguidores, héroes que son vasallos y que por lo tanto obran siempre en favor de un bien o una institución superior. Los fascismos europeos se aprovecharon de este modelo. Y por si alguna duda cabía, el final de la segunda guerra mundial acabó, para la cultura occidental, con los héroes atávicos y autárquicos de corte germánico. El héroe ya nunca más fue el rey, sino el soldado, la persona que sirve a un ejército, a un Estado. El héroe nunca es, por utilizar un relato frecuente

35 «Wie Siegfried unter dem hinterlistigen Speerwurf des grimmigen Hagen, so stürzte unsere ermattete Front; vergebens hatte sie versucht, aus dem versiegenden Quell der heimatlichen Kraft neues Leben zu trinken» (cit. en MüNKLER / STORCH, cit. nota 34, p. 86).

36 V. Millet, «¿Por qué los Nibelungos, señor Fritz Lang?», en J. Ll. Martos y M. GarCÍA Sempere (eds.), L’Edat Mitjana en el cinema i en la novel.la històrica, Alicante, Institut Interuniversitari de Filologia Valenciana, 2009, pp. 447-474. H.B. Heller, «Nur dann überzeugend und eindringlich, wenn es sich mit dem Wesen der Zeit deckt'. Fritz Langs Nibelungen-Film als Zeitbild», en Heinzle / Klein / Obhof (cit. nota 28), pp. 497-509. Ch. Kiening y C. Herberichs, «Fritz Lang: Die Nibelungen (1924)», en C. Kiening y H. Adolf (eds.), Mittelalter im Film, Berlín, de Gruyter, 2003, pp. 189-225. 
en el cine americano, el presidente de los Estados Unidos, sino quien lo salva o protege de amenazas internas o externas. Se ha impuesto el modelo artúrico, donde el rey tiene escaso protagonismo, pero representa un sistema al que los héroes sirven. Un sistema heroico en el que la sumisión al Derecho y a un sistema moral se presupone de antemano y donde los intentos de imponer la ley del más fuerte se conciben como desviaciones. Desde Rambo y Bourne hasta La guerra de las galaxias. Y donde haya oro por medio ya no es un símbolo de poder, capaz de atraer guerreros, sino dinero para gastar y llevar una vida acomodada.

Pero Sigfrido no ha desaparecido de la cultura alemana, sólo se ha transformado para seguir alimentando relatos. Donde lo encontramos ahora es en el ámbito de la narrativa infantil, incluso de las parodias antiheroicas y dragonofílicas ${ }^{37}$. Y naturalmente en el ámbito phantasy ${ }^{38}$, que no es otra cosa que el regreso ficcional al universo heroico que nos redescubrió el gran medievalista Tolkien. El relato de Sigfrido lo tiene todo para un superhéroe del género phantasy: sus orígenes en un país exótico, su fuerza, su formación en una herrería del bosque, su lucha contra el dragón, el rescate de la princesa y otras muchas aventuras que se han contado sobre él en textos medievales. Pero en este género, Sigfrido es todavía un personaje en busca de un buen autor.

RECIBIDO: 26-12-2019; ACEPTADO: 29-07-2020

37 Por ejemplo K. KoInegg, Der Schatz der Nibelungen: Hörspiel über Siegfried, dem Drachentöter. Dortmund, Igel Records, 1998; K. ReICHert, Siegfried-Die wahre Kunde vom Drachentöter. Königswinter, New School, 2005.

${ }^{38}$ Destaca aquí el personaje 'Schtauffen' del videojuego japonés SoulCalibur (https://soulcalibur.fandom.com/wiki/Siegfried; última consulta 26/6/2021). 